\title{
Augusto dos Anjos e a crítica da ciência pela ciência: um testemunho do debate cientificista na Primeira República através da poesia
}

\section{Augusto dos Anjos and the critique of science by the science: a testimony of the scientism debate in the First Republic through the poetry}

\author{
Daniel Henrique da Mota Ferreira \\ Mestrando de Sociologia no Instituto de Estudos Sociais e Políticos da Universidade \\ Estadual do Rio de Janeiro (IESP-UERJ). Bolsista Nota 10 FAPERJ. \\ danielhf@iesp.uerj.br \\ orcid.org/0000-0003-2129-6050.
}

Resumo. O presente trabalho procura analisar o debate sobre o cientificismo no início da República, período da institucionalização das ciências, através da obra de Augusto dos Anjos. Para tanto, o artigo estipula a partir das tipologias de Sevcenko como a literatura entendeu o debate da época e como Augusto dos Anjos conseguiu, em uma posição intermediária, traçar uma crítica ao cientificismo por meio de sua utilização consciente. Ao fim, propõe-se que sua contribuição ao debate da época demonstra as qualidades da poesia como forma de testemunho e como produtora de reflexividade.

Palavras-chave: Modernidade. Brasil. 1 ${ }^{a}$ República. Cientificismo. Augusto dos Anjos

Abstract. This article analyzes the scientism debate in Brazil's Firs Republic, period in which science has been institutionalized, through Augusto dos Anjos' ouvre. In this regard, the paper stipulates, based on Sevcenko's typologies, how literature understood the debate of the time and how Augusto dos Anjos managed, in an intermediate position, to draw a critique of scientism through its conscious use. In the end, it proposes that his contribution to the time debate shows poetry's qualities as a way of testimony and as a reflexive producer.

Keywords: Modernity. Brazil. First Republic. Scientism. Augusto dos Anjos. 


\section{Introdução}

Autor de uma imensa fortuna crítica, Augusto dos Anjos foi um dos maiores nomes da poesia brasileira no início do século XX. Sua inovação não foi tanto na forma, mas no conteúdo, o qual, pela maneira singular com que tratou determinadas temáticas, levou-o a ser alçado ao panteão dos grandes escritores brasileiros como um antigo moderno (HARDMAN, 1996).

O conteúdo dos seus textos é um resultado do contexto de sua época. Nesta relação entre texto e contexto, ao se voltar para a sociedade e questioná-la, ele coloca a poesia na posição reflexiva, isto é, na posição de se compreender enquanto parte da sociedade e procurar nela intervir, monitorando os caminhos em que ela pode seguir (GIDDENS, 1991). Nesse empenho da modernidade, acreditamos que a literatura e sua crítica promovem a esfera pública (HABERMAS, 2014), tecendo seus debates, não em uma perspectiva fora de lugar (SCHWARZ, 2000), ou deslocada, mas intrínseca aos problemas nacionais na sua época.

Nesse ponto, acreditamos que a poesia de Augusto dos Anjos, enquanto "poeta cientificista", nos ajuda a pensar a conjunção da ciência com a ideologia do positivismo que estava presente na época. Sugere-se que o autor aborda o discurso, buscando exagerá-lo para poder criticá-lo. Para tanto, o artigo primeiro busca abordar as tipologias de Sevcenko para abordar os escritores da Primeira República. Após, analisaremos os textos do autor e demonstraremos a singularidade com que ele travou o debate à época. Na conclusão, ratificamos o argumento da importância do testemunho crítico de Augusto dos Anjos para pensar a ideologia cientificista e seus problemas.

\section{Vitoriosos e Derrotados na Aurora Republicana}

Para compreender o testemunho de Augusto dos Anjos, vale pensar contra o que se voltava o seu discurso. Na época, podemos notar pela caracterização de Sevcenko que a característica fundamental do literário era ter a literatura como "uma missão". Uma missão que visasse incidir no debate para poder auxiliar na transformação da sociedade.

Deste modo, o grupo como um todo poderia ser definido por essa "predisposição temática e política", a qual revelava "sua afinidade profunda com a irradiação insólita das energias econômicas e culturais que procediam da Europa em escala crescente ao longo dos três últimos decênios do século XIX”. (Sevcenko, 2003, P. 99)

Tais energias oriundas da Europa poderiam ser compreendidas como o projeto de modernidade, o qual animará a discussão tanto pelo seu caráter de ruptura da ordem social, como pela sua consciência da questão nacional que precisava ser debatida ( HARDMAN, 1996, P. 290-291). Esse era o plano comum a partir do qual se instaura a divergência.

De um lado havia aqueles que se associavam com o discurso republicano e modernizador da época. Estes, imbuídos de um ideal positivista, tenderiam a enxergar o paradigma 
europeu como o caminho a ser trilhado. Tais personagens foram chamados por Sevcenko de vencedores, dada sua capacidade de se inserir nos altos círculos das elites nacionais, aparecendo como grandes figuras públicas (SEVCENKO, 2003, P. 131). Eram escritores e jornalistas, difusores de informação.

A ideologia republicana presente nesses autores era a crença positivista em um mundo das Ciências e da Ilustração. Esse ideal seria importante para institucionalização da ciência no Brasil, pois ele identificaria nas "formas de sociabilidade, nos arranjos institucionais e nos conhecimentos gerados pela atividade científica a chave para a reorganização da sociedade brasileira" (FERREIRA, 2007, P. 2).

Se por um lado o positivismo auxiliou na institucionalização da ciência no país, também é de se observar que tal ideologia propagou em nossos círculos intelectuais a crença etnocêntrica em que as diversas culturas eram apenas estágios de uma mesma linha civilizacional, em cujo topo se encontraria a Europa. Exemplos desse fato são os trabalhos de Silvio Romero, crítico literário aguerrido, cujo trabalho buscou entender como que as condições nacionais determinavam os resultados da literatura(ROMERO,1902); e Nina Rodrigues, o qual procurou entender os males brasileiros por meio do entrecruzamento de raças (RODRIGUES, 2008).

O segundo grupo, porém, não enxergava o ideal positivista e modernizador com bons olhos. Era um grupo de autores marginalizados, cuja entrada nos grandes salões era vedada, justamente por suas duras críticas ao mundo. Tais autores teriam, de acordo com Sevcenko, uma divisão interna entre aqueles que resignavam-se ante àquilo que viam como um mal consumado oriundo da modernidade e aqueles que eram inconformados com a nova ordem das coisas e que reagiam "pela combatividade permanente" (SEVCENKO, 2003, P. 133).

Dentro destes três grupos, onde poderia se encaixar a obra de Augusto dos Anjos? Tal classificação pode nos ser útil para saber de que modo o testemunho dele procurava interferir e se inserir no mundo da época.

\section{O Testemunho de Augusto dos Anjos: entre dois mundos}

Sua carreira lembra a de um vencedor. Estudou no liceu paraibano e se formou na faculdade de Direito de Recife, em 19071. Neste período, ele travará contato com Sílvio Romero, o qual acreditava que a poética tinha que estar "ligada às luzes do seu tempo" (Romero apud Sabino, 2006,P. 24). Lembremos que Romero acreditava que a literatura era influenciada pelos meios externos e, como o tempo agora era o do cientificismo, era necessário pensar uma literatura que pudesse ser a expressão deste momento.

A posição de Augusto como vitorioso poderia assim ser registrada no interesse pela ideologia cientificista da qual este mesmo se utilizará para se opor ao idealismo, característica dos românticos e dos simbolistas, como se pode ver nos versos do poema "natureza íntima" dedicado ao poeta idealista Farias Brito. Neste aparece: 
Cansada de observar-se na corrente

Que os acontecimentos refletia,

Reconcentrando-se em si mesma, um dia,

A Natureza olhou-se interiormente!

Baldada introspecção! Noumenalmente

O que Ela, em realidade, ainda sentia

Era a mesma imortal monotonia

De sua face externa indiferente!

E a Natureza disse com desgosto:

“Terei somente, porventura, rosto?!

“Serei apenas mera crusta espessa?!

"Pois é possível que Eu, causa do Mundo,"

"Quanto mais em mim mesma me aprofundo,"

“Menos interiormente me conheça?”. (Anjos apud Sabino, 2006, P. 40)

Neste trecho o que se percebe é a crítica ao pensamento idealista na ironia (baldada introspecção) com a qual o autor trata a busca da Natureza pela sua Essência. Ao invés de encontrar o noumeno na sua introspecção, encontra a mesma "imortal monotonia/ de sua face externa indiferente", isto é, percebe o vazio da introspecção da busca de uma Essência para além da matéria e, portanto, da empiria. Segundo Sabino:

\begin{abstract}
Augusto dos Anjos sugere que esse tipo de investigação não apenas conduz a conhecimentos falsos, como também dificulta a aquisição de conhecimentos reais e prováveis - positivos - baseados nos fenômenos cognoscíveis: quanto mais a natureza procura compreender esse "mundo interior" (quanto mais em mim mesma me aprofundo), menos conhecimento ela adquire (menos interiormente me conheça). Não há um mundo interior a ser descoberto, mas apenas o mundo factual (Sabino, 2006 P. 40)
\end{abstract}

Isto exposto, podemos concordar com Sabino e dizer que este é o maior poeta cientificista (Sabino, 2006, P. 84). Todavia, seria isso o bastante para tornar o poeta paraibano um tipo puro de vencedor? Seguindo o argumento de Sevcenko, o que caracteriza os vencedores é a sua afinidade com o discurso hegemônico na época, o qual renderia a sua entrada nos altos círculos. Tal discurso, como já observado, tinha a ideia de uma civilização moderna, de 
uma 'Europa dos trópicos" como seu ideal. Há aqui um entusiasmo pela Razão entre a nossa elite e uma crítica desta à composição de nosso povo: inculto, crente e ingênuo.

Todavia, o autor não poderia de fato ser considerado um entusiasta do mundo atual. Ao contrário, sua influência cristã se mostra presente na sua crítica contundente a essa modernidade que o materialismo científico parecia carregar. Não será por outro motivo que entre os grandes inimigos da tendência do homem, o eu lírico parece criticar de forma contumaz o filósofo moderno, enquanto "representante do cientificismo mecanicista que ameaçava a crença no espírito e na transcendência humana" (SANTOS, 2007).

Como exemplo, comecemos pela análise de Psicologia de um Vencido, um dos seus trabalhos mais famosos. Nesse clássico, o autor traz o discurso científico para a sua poesia, mas o faz para criticá-lo: "Eu, filho do carbono e do amoníaco/ Monstro de escuridão e rutilância/ Sofro, desde a epigénesis da infância/ A influência má dos signos do zodíaco." Ao pôr a lupa científica sobre o homem, retira dele todo o encanto e os seus mistérios e torna o "filho do carbono e do amoníaco" em um "monstro de escuridão e rutilância" (Anjos, 1998, P. 13). Augusto dos Anjos escreve ainda que o "verme - este operário de ruínas _-" "Anda a espreitar meus olhos para roê-los/ E há de deixar-me apenas os cabelos/ $\mathrm{Na}$ frialdade inorgânica da terra!”. O discurso com jargões científicos aponta que não há nada após a morte.

Está aí a característica da poética científica para Sabino (2006, P. 84): o autor se apropria para questionar a ausência do transcendental. Assim, o discurso de vencedor do progresso, é invertido na psicologia, fazendo do autor, assim como seu eu-lírico um vencido, um derrotado. Mais especificamente, aproxima-se do subgrupo dos derrotados chamado de boêmios na obra de Sevcenko ( 2003, P. 133). Tanto ele quanto o grupo se opunham à vitória do materialismo e do individualismo, sempre olhando estas duas condições com desprezo evidente que o coloca próximo ao simbolismo de Cruz e Sousa, o qual é considerado por Sevcenko o expoente desse grupo.

Consideremos também o poema "os doentes" por sua crítica à modernidade e aos filósofos modernos. Nele, o eu lírico denuncia o progresso brasileiro, o qual foi feito à custa do sangue das outras raças e o evolucionismo como doutrina. Já na primeira parte escrevia: " $\mathrm{E}$ via em mim, coberto de desgraças/O resultado de bilhões de Raças / Que há muito desapareceram!" (Anjos, 1998, P. 61). O brasileiro era o resultado da mistura de raças, como colocava o discurso da época. Porém, tal não foi feito como uma mistura ou mescla, que possam propor uma ideia de harmonia, mas sim por meio de um conflito. A raça branca é aquela que prepondera, porque justamente foram as outras exterminadas, desaparecidas.

Para vencedores como Romero (1912), o momento da miscigenação do brasileiro traria a preponderância do homem branco, na medida em que o Brasil e, com ele, do progresso.. Mas para Augusto dos Anjos, o caminho da preponderância do branco é, em si, um dos grandes crimes que marcam a consciência brasileira. Na terceira parte dos doentes esse ponto é evidenciado. Nele, o eu-lírico considera que a alma brasileira sofria. Ele dizia encher uma "tétrica imagem" da "carcaça esquecida de um selvagem". E prossegue:: 


\author{
A civilização entrou na tava \\ Em que ele estava. O gênio de Colombo \\ Manchou de opróbrios a alma do mazombo, \\ Cuspiu na cova do morubixaba! \\ E o índio, por fim, adstrito à étnica escória, \\ Recebeu tendo o horror no rosto impresso, \\ Esse achincalhamento do progresso \\ Que o anulava na crítica da História!” (Anjos, 1998, P. 71)
}

Augusto dos Anjos narra a invasão europeia em terras brasileiras. Claro está que ele se considera civilizado, ao se opor à figura do selvagem esquecido no Amazonas. Todavia, como brasileiro, destaca que a vitória da colonização europeia, tendo sido feita ao custo do sangue dos índios e riscando-os da História, criou uma marca na própria alma brasileira. Esta marca é um dos motivos pelos quais a poesia se chama "os doentes". São doentes os brasileiros, ao terem em si a morte e o sangue de diversas raças na sua construção e ao fecharem os seus olhos às mazelas desta raça e apenas enxergar em si o Europeu triunfador. A questão racial aparece também pela denúncia no que tange aos resultados da escravidão, a qual termina por apontar um branco longe dos ideais de um civilizador, mas sim mais próximo a um bárbaro no tratamento dado à raça negra e a suas mulheres. Este é o pensamento que o autor expõe na parte VIII do mesmo poema, na qual escreve:

E hirto, a camisa suada, a alma aos arrancos,

Vendo passar com as túnicas obscuras,

As escaveiradíssimas figuras

Das negras desonradas pelos brancos;

Pisando, como quem salta, entre fardos,

Nos corpos nus das moças hotentotes

entregues, ao clarão de alguns archotes,

A sodomia indigna dos moscardos;

Eu maldizia o deus de mãos nefandas

Que, transgredindo a igualitária regra

Da Natureza, atira a raça negra

Ao contubérnio diário das quitandas! (Anjos, 1998 [1912], P. 86)

Revista Scientiarum Historia, 2018, v.1: e218 
O poeta paraibano observa a objetificação do negro e do seu corpo ao comparar as mulheres aos fardos (Como quem salta, entre fardos/ Nos corpos nus das moças hotentotes). A denúncia da escravidão que aqui se coloca, uma doença indelével do corpo brasileiro, foi uma crítica da grande maioria dos escritores desta mesma época, preocupados que estavam em ver sua literatura como missão. Entretanto, aqui, diferentemente da "Praga" de Coelho Neto, o autor não expõe o negro como uma pessoa envolta em superstições, a qual deve ser liberada, mas tem em si um pensamento ainda obscuro e místico que precisava ser combatido pela nova República. Ao contrário, aquele que é um problema é o branco e o deus cruel que viria a transgredir a igualitária regra/ Da Natureza, ou seja, a visão liberal da igualdade entre os homens calcada no próprio Direito Natural foi deturpada, extinta e desfigurada.

$\mathrm{O}$ arremate final ao pensamento vitorioso se faz presente na sua crítica aos próprios evolucionistas e cientificistas. Isto é marcante na continuação do poema "os doentes", onde o autor relata que "Os evolucionistas benfeitores Que por entre os cadáveres caminham,/iguais a irmãs de caridade, vinham / Com a podridão dar de comer às flores!" (Anjos, 1998 [1912], P. 84). Os evolucionistas não ligavam para as demais raças, para o surdo grito dos desfavoráveis. Por isso, o autor abre este poema se perguntando sobre aquilo que Haeckel e Spencer, dois evolucionistas, não entendem. $O$ que não compreendem é a própria noção de espiritualidade, reduzindo tudo a um plano imanente em que uma vida apenas sucede a outra, sem juízo de valores. Esse é um momento conflituoso em seu pensamento, posto que é deles que ele retira a sua reflexão. Mas é ao condicionar a ciência a Bíblia - a outra força do Brasil da época- que o eu-lírico faz valer o seu romantismo e sua crítica à modernidade.A doença e morte presentes na matéria não são por eles compreendidas, devido à limitação natural do discurso evolucionista de enxergar os horrores da matéria e os problemas na construção histórica de um povo. Os filósofos se tornam, portanto, inimigos do eu lírico, na medida em que" inutilidade de suas indagações, fadadas, por falta de ânimo ou crença metafísica" tende "à percepção superficial do mecanismo das coisas".

\section{Considerações Finais}

A poesia de Augusto dos Anjos é em si uma construção singular de sua época, quer seja pela forma como pelo conteúdo. Nem derrotado e nem vencedor, Augusto dos Anjos aceitava os preceitos científicos e, por isso mesmo sua poética é ainda mais significativa por demonstrar a tensão de um caminho que, ao se fazer materialista, negaria outros valores para a própria humanidade. É essa sua singularidade que nos permitiu captar uma forma singular de interpretação das grandes discussões do início do séc XX: Ciência, progresso, modernização, a questão das raças e o ideal europeu. Todas estas questões que convulsionaram à época tiveram seu testemunho na lira de Augusto dos Anjos. 


\section{Referências}

AGUIAR, A. A. de. Avaliação da microbiota bucal em pacientes sob uso crônico de penicilina e benzatina. 2009. Tese (Doutorado em Cardiologia) - Faculdade de Medicina, Universidade de São Paulo, São Paulo, 2009.

ANJOS, A. dos. EU e Outros Poesias. 42 ed. Rio de Janeiro: Civilização Brasileira, 1998. disponível em: http://www.culturabrasil.org/zip/eu.pdf

FERREIRA, L. O. O Ethos positivista e a institucionalização da Ciência no Brasil no Início do Século XIX. Fênix - Revista de História e Estudos Culturais, Uberlândia, v. 4, n.3, p. 1-10, jul./ ago./ set. 2007.. acessado em 14/07/2018. Disponível em: $</$ www.arca.fiocruz.br/handle/icict/25486>

GIDDENS, A. As Consequências da Modernidade. tradução de Raul Fiker. - São Paulo: Editora UNESP, 1991

HABERMAS, J. Mudança Estrutural da Esfera Pública. Trad. Denilson Luís Werle. $1^{\mathrm{a} e d . S a ̃ o ~ P a u l o: ~ E d i t o r a ~ u n e s p . ~} 2014$

HARDMAN, F. F. Antigos Modernos. In: NOVAIS, Adauto (Org.). Tempo e História. 2a reimp. São Paulo, Companhia das Letras. 1996

PEREIRA, L. A. de M. Cousas do sertão: Coelho Netto e o tipo nacional nos primeiros anos da República. Revista História Social, . N 22 e 23, Pp.83-101. 2012. acessado em 10/07/2018. Disponível em: $<$ https://www.ifch.unicamp.br/ojs/index.php/rhs/article/view/1204/837>

ROMERO, S. História da Literatura Brasileira. 2a ed melhorada pelo autor. Vol. 1. Rio de Janeiro: H. Garnier, Livreiro-editor. 1902

RODRIGUES, R. N. Mestiçagem, Degenerescência e Crime. História, Ciência e Saúde Manguinhos , 15, 1151-1180. 2008

SABINO, M. P. Augusto dos Anjos e a poesia Científica.2006. 93 Fl.Dissertação de mestrado. Faculdade de Letras. UFJF. Juíz de Fora. 2006

SAntos, G. S. A morbidez poética em EU de Augusto dos Anjos. Disponível em: http://www.jornaldepoesia.jor.br/ginaldosilva2.html

SEVCENKO, N. Literatura como missão: tensões sociais e criação cultural na Primeira República. São Paulo: Brasiliense,1985. 